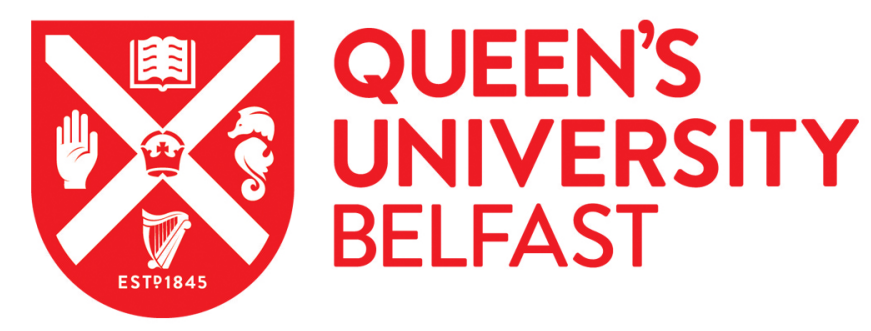

\title{
Understanding the impact of high penetration residential batteries with low carbon technologies on the low voltage networks
}

\begin{abstract}
Mohamed, A. A. R., Best, R., Liu, X. A., \& Morrow, D. J. (2021). Understanding the impact of high penetration residential batteries with low carbon technologies on the low voltage networks. In The International Conference \& Exhibition on Electricity Distribution (CIRED): Proceedings (CIRED Biennial Conference Proceedings).
\end{abstract} https://doi.org/10.1049/icp.2021.1954

Published in:

The International Conference \& Exhibition on Electricity Distribution (CIRED): Proceedings

\section{Document Version:}

Peer reviewed version

Queen's University Belfast - Research Portal:

Link to publication record in Queen's University Belfast Research Portal

Publisher rights
@ 2021 IET.
This work is made available online in accordance with the publisher's policies. Please refer to any applicable terms of use of the publisher.
This work is made available online in accordance with the publisher's policies. Please refer to any applicable terms of use of the publisher.

\section{General rights}

Copyright for the publications made accessible via the Queen's University Belfast Research Portal is retained by the author(s) and / or other copyright owners and it is a condition of accessing these publications that users recognise and abide by the legal requirements associated with these rights.

Take down policy

The Research Portal is Queen's institutional repository that provides access to Queen's research output. Every effort has been made to ensure that content in the Research Portal does not infringe any person's rights, or applicable UK laws. If you discover content in the Research Portal that you believe breaches copyright or violates any law, please contact openaccess@qub.ac.uk. 


\title{
UNDERSTANDING THE IMPACT OF HIGH PENETRATION RESIDENTIAL BATTERIES WITH LOW CARBON TECHNOLOGIES ON THE LOW VOLTAGE NETWORKS Ahmed A.Raouf Mohamed *, Robert J. Best, Xueqin Liu, D. John Morrow
}

\author{
EPIC Research Cluster, School of Electronic, Electrical Engineering and Computer Science, \\ Queen's University Belfast, Belfast, UK \\ *amohamed06@qub.ac.uk
}

\begin{abstract}
Keywords: BATTERY ENERGY STORAGE SYSTEMS, DISTRIBUTION SYSTEM OPERATORS, ELECTRIC VEHICLES, LOW VOLTAGE RESIDENTIAL NETWORKS, SOLAR PHOTOVOLTAIC
\end{abstract}

\begin{abstract}
The integration of solar photovoltaic (PV) and electric vehicles (EVs) is increasing apace in residential low voltage networks. This rapid deployment has raised concerns to the distribution system operators (DSO) due to the technical issues associated with the high penetration of these technologies. In addition, battery energy storage systems (BESS) have attracted many prosumers due to their capabilities in cutting electricity bills by achieving a profitable energy arbitrage between the PV overgeneration and demand. In this paper, the impact of BESS deployment on a wide scale at the residential level is analysed for different operation strategies. Three BESS strategies are simulated for one-year for a residential feeder located in Northern Ireland. The results show that the integration of BESS can support the network by mitigating the negative impacts of PVs and EVs. However, their unsupervised operation on a wide scale can disadvantage network operation. Hence, heuristic managementbased incentive schemes should be established by DSOs that assure safe network operation and prosumers profitability.
\end{abstract}

\section{Introduction}

At the low voltage residential network (LVRN), rooftop solar photovoltaics (PVs) is giving rise to technical challenges with significant overgeneration infeed during the summer when the network is typically lightly loaded. In addition, the electrification of transport and heat using electric vehicles (EVs) and heat-pumps exacerbate the situation by increasing the peak demand significantly, especially during the winter. The negative impacts of these low carbon technologies (LCTs) with high uptakes at the LVRN can be observed in voltage violations and unbalance, thermal overloading, and high phase and neutral losses [1]. These challenges have driven distribution system operators (DSO) to adopt innovative solutions to mitigate the drawbacks of high LCTs penetrations. One of these solutions is by incentivizing behind the meter battery energy storage systems (BESS) in return for supporting the network, such as the project reported in [2]. This project proved the efficacy of residential BESS in supporting network operation and flexibility. Residential BESS are mainly installed to minimize the electricity bill by maximizing the PV self-consumption and achieving a profitable energy arbitrage in the presence of time of use (ToU) tariffs which attracted many prosumers due to the unattractiveness of the current renewable incentives.

It is anticipated that the deployment of residential BESS will increase in the next few years due to their ability to reduce electricity bills, the downward trend in their capital cost and the provision of services to the LVRN [2-7]. The operation strategies of these units can greatly affect their benefits to the network from the DSO's perspective. For instance, an autonomous BESS installed in a dwelling will be operated to maximize the customer's profitability by charging during the PV period and discharges when the demand exceeds the generation. This operation scheme does not focus on mitigating the overvoltage during the peak PV period, instead, the BESS charges when there is excess in the generation, hence, the BESS can be fully charged before peak PV generation occurs. The same for discharging, the BESS discharges when the demand exceeds the generation during high ToU tariff without focusing on the peak.

This operation framework is understandable as the customers focus on their profitability; hence, BESS owners may be incentivized by the DSO to support LVRN during congestion periods. This can be achieved by assigning specific units in the LVRN to be ready to (dis)charge according to signals from the DSO [4]. However, these schemes require expensive and complex ICT infrastructure which is not affordable for all networks in addition to high compensations paid to the BESS owners. Moreover, other methods utilise the look-ahead forecasts to control the BESS [5]. However, the forecasting-based methods do not always guarantee practical solutions due to the forecasting errors besides its associated complexity. Furthermore, decentralized control techniques can be applied to support network operation [6]. Yet, these techniques require many inputs to operate efficiently and not all BESS controllers can easily be adjusted for these techniques. The simpler scheme is to use heuristic operation strategies by persuading BESS owners to operate their units according to pre-defined thresholds in return for reasonable compensations [2]. Yet, 
the selection of these thresholds should be determined properly to maximize the benefits.

It can be observed that several studies addressed the management of residential BESS to benefit the LVRN [2-6]. However, none of the studies published so far considered the long-term operational impact of their methods for the widescale BESS deployment on the LVRN in the presence of different LCTs. Regarding the impact of residential BESS on the LVRN, the impact of high uptake aggregatorcontrolled BESS on the LVRN has been addressed in [7]. The study showed that several network violations may exist with high penetrations of market-oriented residential BESS. Yet, to the authors' knowledge, the autonomous operation impact of high uptake residential BESS on the LVRN has not been addressed in the literature to date.

This paper investigates the impacts of autonomous residential BESS deployed on a wide scale for different heuristic operation strategies in the presence of PVs and EVs on the LVRN. The proposed work considers both the customers and DSO benefits. A case study is conducted over a full year for an actual LVRN that aims to answer the question: How can the residential BESS be operated to benefit both the customers as well as the DSO with lower costs, incentives, and complexity?

\section{Modelling}

\subsection{Test Feeder}

A $397 \mathrm{~m}$ feeder with 6 nodes is adopted from a residential network located in Northern Ireland representing typical LVRN in the UK. The feeder is a three-phase four-wire and supplies 30 households distributed on 5 nodes as shown in Fig. 1. Each household is supplied by a single-phase, such that 2 houses/phase/node. The feeder data and specifications were provided by Northern Ireland Electricity Networks (NIE Networks), who are the DSO of Northern Ireland.

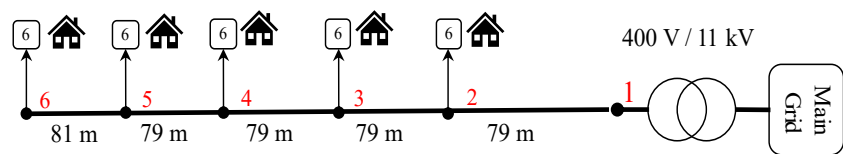

Fig. 1 Test feeder simplified schematic

\subsection{Load and LCTs Profiles}

\subsubsection{Households Consumption}

One-year half-hourly energy profiles for 30 houses were obtained from smart meter measurements of Low Carbon London (LCL) dataset by UK Power Networks [8].

\subsubsection{EV Patterns}

In this work, two EV charger ratings are considered; $3 \mathrm{~kW}$ and $7 \mathrm{~kW}$, and the charging patterns are developed using a probabilistic model. The charging start time is treated as a cumulative distribution function (CDF) using one-year measurements of a residential EV from the LCL dataset [8]. For each day, the first hour of the EV charging cycle is obtained. Afterwards, the daily values for one year are treated as a normal distribution function with $(\mu=12.9478$, $\sigma=8.4437$ ). The charging end time is determined using the EV battery state of charge (SoC) and charger rating. The
SoC is treated as a CDF $(\mu=3.2125, \sigma=0.6537)$ related to the daily travel distance assuming that the daily travel distance of an EV is identical to the traditional vehicle in agreement with [9] using the daily travel data from [10].

\subsubsection{PV Patterns}

Since PV generation patterns tend to be similar in the same geographical area, one-year generation PV profile for a house located in Northern Ireland was obtained for the $4 \mathrm{kWp}$ size from [11] and scaled according to each household's PV system. The PV size $\left(P V_{\text {size }}^{h}\right)$ installed at each household is calculated using the average daily household consumption $\left(E_{\text {avg }}^{h, d}\right)$, average sun hours $\left(T_{\text {avg }}^{s}\right)$, and efficiency $\left(\eta_{P V}\right)$ :

$$
P V_{\text {size }}^{h}=\frac{E_{\text {avg }}^{h, d}}{T_{\text {avg }}^{s}} \times \eta_{P V}
$$

Where $\eta_{P V}=1.2$ is an efficiency factor to compensate for the PV losses, and $T_{a v g}^{s}$ is taken as 3.3 for Belfast, UK [12].

\subsubsection{BESS Patterns}

To generate BESS patterns, real-time strategies are developed that utilize rules and thresholds to (dis)charge the BESS. These strategies require the details for a BESS $b$ represented in the capacity $\left(E_{b}\right)$, maximum depth of discharge (DoD), BESS system efficiency $\left(\eta_{b}\right)$, and power rating $\left(P_{b}^{\max }\right)$. These strategies update the SoC at time $\mathrm{t}$ as:

$$
S o C_{t, b}=S o C_{t-1, b}+\frac{P_{t, b}^{c h} \eta_{b} \tau}{E_{b}}-\frac{P_{t, b}^{d i} \tau}{E_{b} \eta_{b}}
$$

Where $P_{t, b}^{c h}$, and $P_{t, b}^{d i}$ are the charging/discharging powers which are limited by the $P_{b}^{\max }$, and $\tau$ is the time interval. The BESS size of each household is determined as:

$$
E_{b}^{h}=E_{\text {avg }}^{h, d} \times(1+(100 \%-D o D)) \times\left(1+\left(100 \%-\eta_{b}\right)\right)
$$

The DoD is taken as $90 \%$, and $\eta_{b}$ is $95 \%$. The BESS sizes obtained from this formula are rounded to the nearest sizes available in the UK market for residential lithium-ion BESS

\section{Methodology}

One-year load profiles are assigned randomly to each house. For the EV patterns, 30 yearly EV charging patterns are generated (15 for $3 \mathrm{~kW}$ charger and 15 for $7 \mathrm{~kW}$ charger) and assigned randomly to each house. The PV and BESS sizes are determined for each house as per the commercial practice using Equations (1) and (3). The distribution of household's consumption profiles and LCTs are given in Table 1. The Economy 7 ToU dual tariff [13] is adopted with $17.19 \mathrm{p} / \mathrm{kWh}$ day rate and $9.59 \mathrm{p} / \mathrm{kWh}$ low rate (1 am-8 am), while $5 \mathrm{p} / \mathrm{kWh}$ is used for the exported power tariff [14].

For the BESS operation strategies, three threshold rulebased strategies are tested. More details on the threshold rule-based strategies can be found in [15]. The first strategy (ST1) focuses only on the customer's profitability, such that the BESS charges when the PV generation exceeds the households' net demand (net $<0$ ) and discharges when the net demand exceeds the generation during high ToU rate period (net $>0$ ). The second strategy (ST2) focuses on benefiting the network with minimum loss in customer's 
profitability. This is achieved by adjusting the BESS controllers to charge during the spring/summer after 10:00 AM to assure that the BESS contributes well in mitigating the PV peak impact, while during the autumn/winter the BESS charges like ST1 due to low PV production during these seasons. For the discharging, the BESS discharges if the demand exceeded the generation after 4:00 PM during the autumn/winter and during the spring/summer the BESS discharges like ST1 as the peak demand is moderate during these seasons.

Table 1 Distribution of Households' consumption, EV charger ratings, PV sizes, and BESS sizes

\begin{tabular}{ccccccc}
\hline $\begin{array}{c}4 \\
\text { House }\end{array}$ & $\#$ & $\#$ & $\begin{array}{c}\text { Average } \\
\text { daily load } \\
{[\mathrm{kWh}]}\end{array}$ & $\begin{array}{c}\text { EV charger } \\
\text { rating } \\
{[\mathrm{kW}]}\end{array}$ & $\begin{array}{c}\text { PV } \\
\text { Size } \\
{[\mathrm{kWp}]}\end{array}$ & BESS \\
{$[\mathrm{kWh} / \mathrm{kW}]$} \\
\hline 1 & 2 & A & 11.54 & 3 & 4.2 & $13.5 / 5$ \\
\hline 2 & 2 & A & 17.88 & 7 & 6.5 & $15 / 3.3$ \\
\hline 3 & 2 & B & 6.06 & 3 & 2.2 & $7.5 / 3.3$ \\
\hline 4 & 2 & B & 9.36 & 3 & 3.4 & $12.3 / 5.5$ \\
\hline 5 & 2 & C & 16.6 & 3 & 6 & $15 / 3.3$ \\
\hline 6 & 2 & C & 20.63 & 3 & 7.5 & $15 / 3.3$ \\
\hline 7 & 3 & A & 5.02 & 7 & 1.8 & $6.3 / 1.7$ \\
\hline 8 & 3 & A & 11.93 & 3 & 4.3 & $13.5 / 5$ \\
\hline 9 & 3 & B & 3.53 & 7 & 1.3 & $4.8 / 2.4$ \\
\hline 10 & 3 & B & 3.14 & 7 & 1.1 & $4.8 / 2.4$ \\
\hline 11 & 3 & C & 11.57 & 7 & 4.2 & $13.5 / 5$ \\
\hline 12 & 3 & C & 7.52 & 3 & 2.7 & $9.6 / 4.2$ \\
\hline 13 & 4 & A & 12.09 & 3 & 4.4 & $15 / 3.3$ \\
\hline 14 & 4 & A & 11.17 & 7 & 4 & $13.5 / 5$ \\
\hline 15 & 4 & B & 12.24 & 7 & 4.4 & $15 / 3.3$ \\
\hline 16 & 4 & B & 9.01 & 7 & 3.3 & $12.3 / 5.5$ \\
\hline 17 & 4 & C & 15.75 & 3 & 5.7 & $15 / 3.3$ \\
\hline 18 & 4 & C & 8.51 & 3 & 3.1 & $9.8 / 5$ \\
\hline 19 & 5 & A & 9.69 & 7 & 3.5 & $12.3 / 5.5$ \\
\hline 20 & 5 & A & 3.54 & 3 & 1.3 & $4.8 / 2.4$ \\
\hline 21 & 5 & B & 6.11 & 7 & 2.2 & $7 / 3$ \\
\hline 22 & 5 & B & 4.86 & 7 & 1.8 & $6.3 / 1.7$ \\
\hline 23 & 5 & C & 10.51 & 7 & 3.8 & $12.3 / 5.5$ \\
\hline 24 & 5 & C & 11.72 & 3 & 4.2 & $13.5 / 5$ \\
\hline 25 & 6 & A & 9.72 & 7 & 3.5 & $12.3 / 5.5$ \\
\hline 26 & 6 & A & 12.55 & 3 & 4.5 & $15 / 3.3$ \\
\hline 27 & 6 & B & 7.66 & 7 & 2.8 & $9.6 / 4.2$ \\
\hline 28 & 6 & B & 17.41 & 3 & 6.3 & $15 / 3.3$ \\
\hline 29 & 6 & C & 10.6 & 3 & 3.8 & $12.3 / 5.5$ \\
\hline 30 & 6 & C & 19.26 & 7 & 7 & $15 / 3.3$ \\
\hline & & & & & & \\
\hline
\end{tabular}

The third strategy (ST3) focuses on benefiting the LVRN according to a set of thresholds. In the spring/summer, the BESS charges after 10:00 AM when the net demand goes below the value of $\frac{-P V_{\text {size }}^{h}}{T_{\text {avg }}^{s s}}$, where $T_{\text {avg }}^{s s}$ is the average spring /summer sun hours (taken as 5 hours for Belfast, UK [12]). In the autumn/winter, the BESS charges like ST1. For the discharging, the BESS discharges when the demand exceeds the value of $\frac{E_{\text {avg }}^{h, d}}{24}$ throughout the year, yet the BESS discharges after 4:00 PM in the autumn/winter. These thresholds are introduced to charge during the PV peak and discharge during the peak load when the demand exceeds the average hourly consumption value. All the previous strategies charge the BESS in the autumn/winter during the night-time ToU rate with $50 \%$ of BESS residual capacity (average PV production drop in autumn/winter w.r.t. spring/summer [16]) using fixed power to achieve a profitable energy arbitrage by optimizing the ToU tariff.

One-year time-series power flow simulations have been conducted for these cases: 1) $0 \%$ LCTs penetration: no PV or EV is installed at households. The LCTs penetration level is a percentage of the total number of households. 2) $100 \%$ LCTs: $100 \%$ of the households with EV and PV. 3) $100 \%$ LCTs and 100\% BESS: all the households are having EV, $\mathrm{PV}$, and BESS. The cases with BESS are conducted for the three BESS operation strategies mentioned previously.

The following indices are considered in the assessment: 1) Node phase-to-neutral voltage, 2) Cable loading, 3) Voltage unbalance (VU), calculated using the approximated factor of the IEC true definition [17], 4) Phase losses, 5) Neutral losses, 6) Annual electricity bill, and 5) BESS degradation.

\section{Results and Discussion}

The results show that the deployment of LCTs may cause severe violations that should be monitored and handled by the DSO. The node voltage rises with the increase of PV penetrations along the feeder, however, node 6 (N6) had the severest impact due to its far location from the transformer. To analyse the impact of LCTs on the node voltage, the voltage distribution during PV period (phase c) as a function of the occurrence probability for N6 throughout the spring/summer is shown in Fig. 2. It is noticed from Fig. 2 that all the strategies managed to improve the voltage distribution around 1 p.u. $(240 \mathrm{~V})$. However, ST1 did not mitigate the events with high voltages. ST2 achieved better results in voltage enhancements compared to ST1. While ST3 effectively managed to reduce the occurrence of overvoltage events compared to the other strategies.
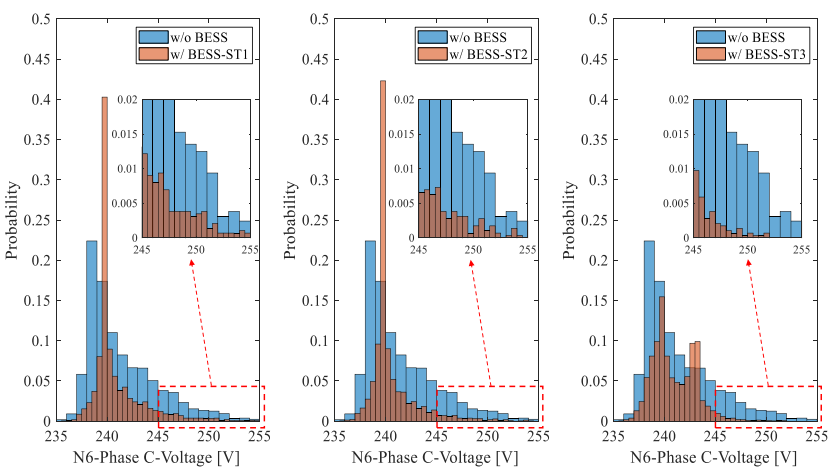

Fig. 2 N6 voltage (phase c) throughout the spring/summer for the case of $100 \%$ LCTs with and without BESS

In the UK, the acceptable voltage limits for the low voltage networks defined by ESQCR are $+10 \% /-6 \%(216.2 \mathrm{~V}-$ $253 \mathrm{~V})$. According to the previous results, phase $\mathrm{c}$ violated the 1.1 p.u. limit for different events throughout the year. ST1 and ST2 decreased these events by $52 \%$, and $68.5 \%$ respectively. While ST3 managed to solve all these violations. Generally, the three strategies managed to reduce the events of voltage above 1.06 p.u. by $65 \%$ (ST1), $70.5 \%$ (ST2), and 84\% (ST3). In order to evaluate the impact of residential BESS and LCTs on the cable loading. The main 
feeder (L1) that connects node 1 to node 2 has been observed and the probability distribution results are given in Fig. 3.
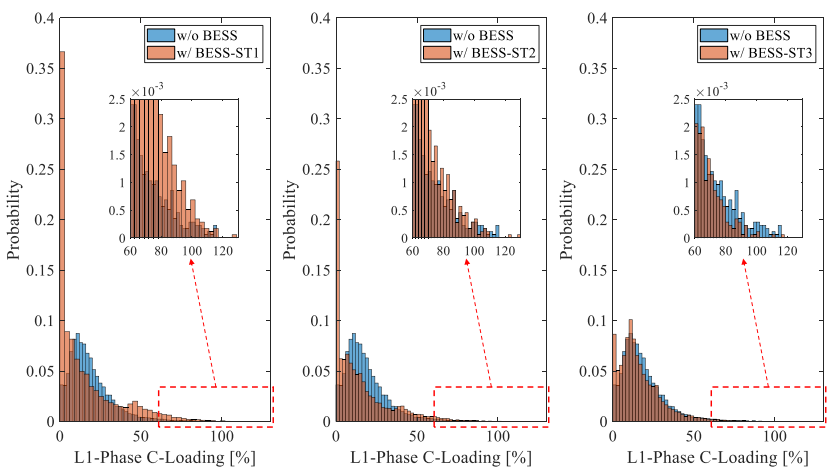

Fig. 3 L1 loading (phase c) throughout the year for the case of $100 \%$ LCTs with and without BESS

As shown in Fig. 3, the existence of PVs and EVs lead to elevated cable loading due to the high demand during winter and the high reverse power flow during the summer. ST3 and ST2 optimized the high loading events, however, ST3 achieved better results by optimizing all the events above $80 \%$ by $54 \%$ compared to ST2 (17.6\%). It can be observed that ST1 did not mitigate cable overloading. This is because ST1 solely considers the customer's profitability and hence, peak events would only be mitigated by accident. Additionally, it is interesting to observe that with high penetration of residential BESS on the network, new peaks can be formed during the night-time ToU rate as many units are charging at the same time combined with other demands, i.e., EV charging and other loads which may lead to congestion. This can particularly be observed with ST1 and partially with ST2, as during these strategies there is no limit for discharging and hence, at the end of the day the BESS will be probably completely discharged and ready to charge during the night. While for ST3, the BESS may not be fully utilised or be idle in the days with low demand and so only a small portion of the capacity is charged at night.

To assess the impact of LCTs and BESS on VU, the VU distribution for nodes 5 and 6 are given in Fig. 4. The increase of LCTs deployment affects the VU due to the unmanaged increase in PV generation and EV demand across the phases. Moreover, the autonomous operation of LCTs and BESS may unintentionally improve the voltage unbalance across the nodes. However, in some cases, the high penetration of these technologies may worsen the VU as shown in Fig. 4, especially with ST1 and ST2.
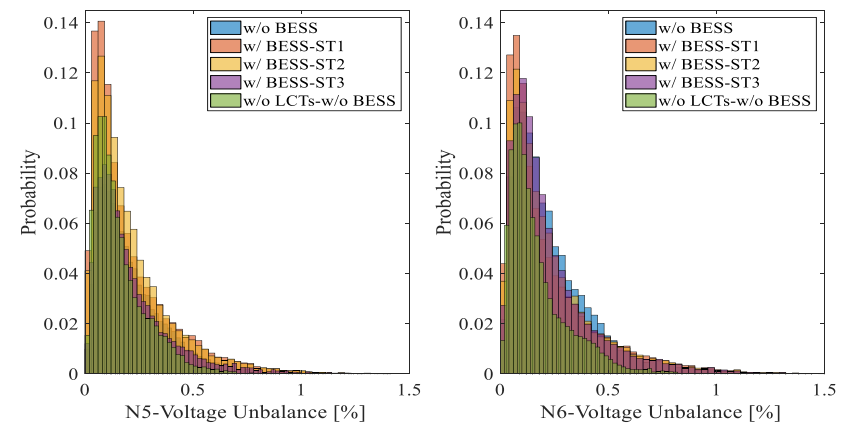

Fig. 4 VU for N5 and N6 throughout the year for the base case and the case of $100 \%$ LCTs with and without BESS
Regarding the losses incorporated in the phases and neutral (see Fig. 5), the existence of LCTs increases the losses in both phases and neutral by $59.5 \%$ and $117 \%$ respectively. The presence of BESS can slightly reduce losses for ST2 and ST3 averagely by $8 \%$. However, ST1 leads to an increase in phase losses by $8.5 \%$ as it does not focus on the peaks besides the frequent charging of ST1 during low ToU tariff.

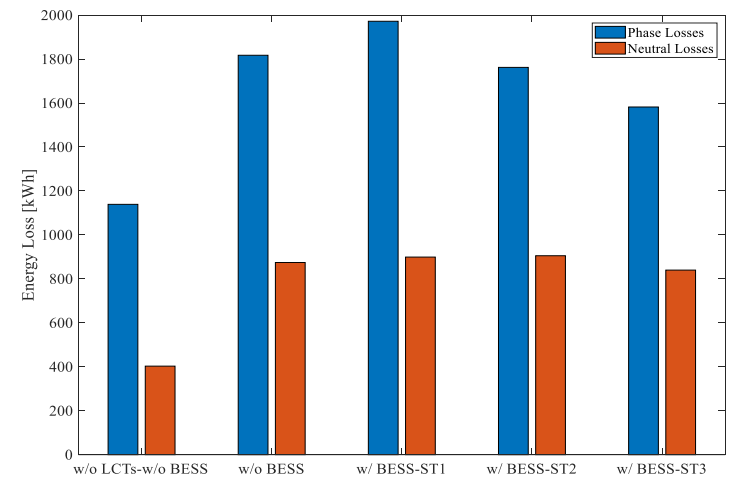

Fig. 5 Total annual energy losses for the LVRN feeder

To evaluate the impact of residential BESS with different strategies on the electricity bill, the annual electricity bill with and without the BESS for the case of $100 \%$ LCTs is shown in Fig. 6 (a). As expected, the best customer profitability can be achieved with ST1, as the electricity bill increased on average by $5 \%$ and $15 \%$ for the case of ST2 and ST3 respectively. The DSO should compensate for this loss in profitability for a return of supporting the network by operating their units using ST2 or ST3.

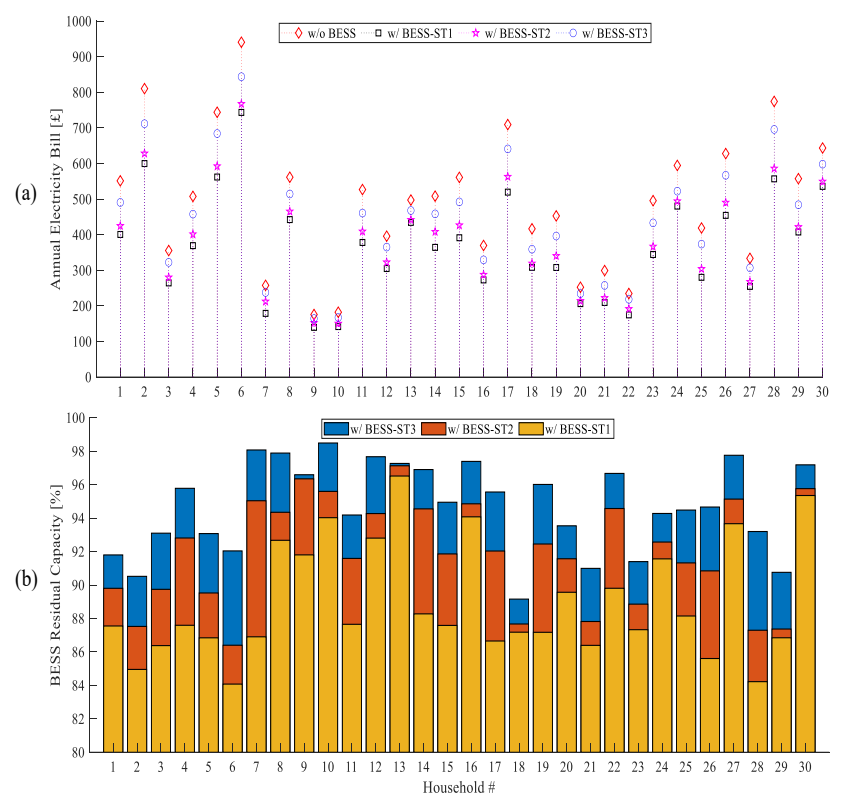

Fig. 6 (a) Annual electricity bill for each household, (b) residual BESS capacity percentage at the end of 10 years

Furthermore, BESS degradation is quantified for each strategy using the cycling ageing model in [18]. The rainflow cycle counting algorithm [19] is used to capture the inputs required for the BESS degradation model at the end of one-year operation, and the results are scaled for 10 years. The residual BESS capacity at the end of 10 years is shown in Fig. 6 (b). The results show that the BESS degrades faster 
with ST1 as the BESS operates more frequent than ST2 and ST3. For ST3, the BESS preserves its capacity for longer periods as the average loss in the BESS capacity throughout 10 years operation of all the households is $5.3 \%$.

\section{Conclusion}

The integration of LCTs on the LVRN will lead to different challenges that should be handled by DSOs as shown in the previous analysis. Relying on residential BESS in mitigating these challenges is an attractive option due to the associated low costs and complexity in addition to the benefits to both customers and DSOs. However, the residential BESS should be managed properly, especially, on a wide scale. This can be achieved unsophisticatedly by operating residential BESS to benefit the network (e.g., using ST3) in return for reasonable incentives from the DSO.

From the results, it should be noted that any incentive scheme should include network losses and BESS degradation. For instance, ST1 will lead to a lower electricity bill, fast degradation, and high energy losses, while ST3 will lead to a higher electricity bill than ST1, slower degradation, and lower energy losses. This should be monetized in the incentives as the BESS operates with ST3 will last longer and has a better impact on network losses compared to ST1.

In the coming years, residential BESS will be a valuable tool for achieving net-zero carbon targets. DSOs should introduce attractive incentives to encourage customers to install these units to benefit the network through proper utilization. This will help in mitigating the negative impacts of LCTs on the network and may avoid or defer the need for conventional reinforcements as well as reducing or preventing the curtailments associated with PV overgeneration or high demand.

For future work, the impact of high uptake of controlled EV on the LVRN as well as the incentive schemes and policies may be investigated in addition to adopting households' consumption profiles and various PV patterns in high temporal resolution for the same geographical area to provide more accurate results.

\section{Acknowledgements}

The authors thank NIE Networks for providing the data used in this paper and for their valuable support. This work is part of SPIRE2 project supported by the European Union's INTERREG VA Programme, managed by the Special EU Programmes Body (SEUPB). The views and opinions expressed in this paper do not necessarily reflect those of the European Commission or the SEUPB.

\section{References}

[1] Mohamed, A.A.R., Morrow, D.J., Best, R.: 'The Deployment of Low Carbon Technologies in Modern Distribution Networks', IEEE PES Innovative Smart Grid Technologies Europe (ISGT-Europe), 2019, pp. 1-5
[2] Hadjiodysseos, P., Van Limpt, S., Alexeev, A.: 'Distributed Storage and Solar Study', CIRED, 2019, paper $n^{\circ} 81$

[3] Alnaser, S.W., Althaher, S.Z., Long, C., Zhou, Y. and Wu, J.: 'Residential community with PV and batteries: Reserve provision under grid constraints', International Journal of Electrical Power \& Energy Systems, 2020, 119, p. 105856

[4] Arkhangelski, J., Mahamadou, A.T., Siano, P. and Lefebvre, G.: 'Evaluating Residential Battery Energy Storage Systems for Up and Down-Regulation', IEEE International Conference on Environment and Electrical Engineering and IEEE Industrial and Commercial Power Systems Europe, 2020, pp. 1-6

[5] Chittur Ramaswamy, P., Schyns, D., De Vos, L., Czajkowski, C., Wilch, M. and Gaul, A.: 'Case study for understanding impact of residential batteries on LV grids', CIRED, 2019, paper $\mathrm{n}^{\circ} 1577$

[6] Petrou, K., Procopiou, A., Ochoa, L.F., Langstaff, T. and Theunissen, J.: 'Residential Battery Controller For Solar PV Impact Mitigation: A Practical and Customer-friendly Approach', CIRED, 2019, paper $n^{\circ} 936$

[7] Hebbeln, I., Pohl, O., Rose, M., Hübner, M.: 'Impact of High Penetration Rates of Home Battery Energy Storage Systems on Low Voltage Grid Planning Strategies', CIRED, Berlin Workshop, 2020, paper $n^{\circ} 445$

[8] 'London Datastore', https://data.london.gov.uk/dataset, accessed November 2020

[9] Zhang, P., Qian, K., Zhou, C., Stewart, B.G., Hepburn, D.M.: 'A Methodology for Optimization of Power Systems Demand Due to Electric Vehicle Charging Load', IEEE Transactions on Power Systems., 2012, 27, (3), pp. 1628-1636 [10] 'National Travel Survey - Department of Transport', https://rb.gy/uf0zmt, accessed July 2020

[11] 'PV output data', https://pvoutput.org/, accessed July 2020 [12] 'Sunshine \& Daylight Hours in Belfast, Northern Ireland, UK Sunlight, Cloud \& Day length', https://www.belfast.climatemps.com/sunlight.php, accessed August 2020

[13] 'Economy 7 Rates - Power NI', https://rb.gy/aeznwh, accessed July 2020

[14] 'Smart Export Guarantee (SEG) - Ofgem', shorturl.at/uDFG9, accessed July 2020

[15] Mohamed, A.A.R., Best, R.J., Liu, X., Morrow, D.J.: 'Domestic Battery Power Management Strategies to Maximize the Profitability and Support the Network', IEEE PES General Meeting, 2021, pp. 1-5, accepted to be published

[16] Pfenninger, S., Staffell, I.: 'Long-term patterns of European PV output using 30 years of validated hourly reanalysis and satellite data', Energy, 2016, 114, pp. 12511265

[17] Pillay, P., Manyage, M.: 'Definitions of Voltage Unbalance', IEEE Power Engineering Review, 2001, pp. 50-51 [18] Xu, B., Oudalov, A., Ulbig, A., Andersson, G., Kirschen, D.S.: 'Modeling of lithium-ion battery degradation for cell life assessment', IEEE Transactions on Smart Grid, 2016, 9, (2), pp. $1131-1140$

[19] ASTM E1049-85: 'Standard Practices for Cycle Counting in Fatigue Analysis', ASTM International, West Conshohocken, 2017 